\title{
Effect of Transversus abdominis muscle training on pressure-pain threshold in patients with chronic low Back pain
}

\author{
Changming $\mathrm{Xu}^{1,2}$, Zhiwei $\mathrm{Fu}^{3}$ and Xueqiang Wang ${ }^{2,4^{*}}$
}

\begin{abstract}
Background: Therapeutic training is the most commonly used treatment methods for chronic low back pain (CLBP), and the use of a pressure biofeedback unit for transversus abdominis muscle ( $\operatorname{Tr} A$ ) training is one of the core muscle training methods. The study aim of this research is to explore the effects of different intensities (sham training, low-intensity and high-intensity) of TrA muscle training on people with CLBP in pressure-pain threshold (PPT).
\end{abstract}

Methods: A total of 45 patients with CLBP were recruited, of whom 44 were included in the analysis. Fifteen, 14, and 15 were included in the sham training group, the low-intensity group, and the high-intensity group, respectively. A pressure biofeedback unit was used in performing a one-time TrA training intervention involving 30 times of $180 \mathrm{mmHg}$ TrA contraction training at high intensity for $10 \mathrm{~min}$ and 15 times of $100 \mathrm{mmHg} \operatorname{TrA}$ contraction training at low intensity for $5 \mathrm{~min}$. The sham training group completed comfort exercises and did not undergo training. The evaluation indicators were as follows: PPT, short-form McGill pain questionnaire, and body surface pain radiation.

Results: High-intensity training could activate more waist core muscles than low-intensity training. Significant changes on PPT (units: $\mathrm{kg}$ ) were observed in the following four muscles immediately after high-intensity training: iliopsoas [0.69 (0.13-1.25) 95\% Cl, $p=0.020$ ]; quadratus lumborum [0.84 (0.23-1.45) 95\% Cl, $p=0.012$ ]; erector spinae [0.66 (0.18-1.15) 95\% Cl, $p=0.011]$; transversus abdominis $[0.70(0.26-1.14) 95 \% \mathrm{Cl}, p=0.004]$, and in three muscles after low-intensity training: quadratus lumborum [0.61 (0.17-1.05) $95 \% \mathrm{Cl}, p=0.009]$; transversus abdominis [0.14 (from -0.15 to 0.43$) 95 \% \mathrm{Cl}, p=0.022]$; piriformis [0.55 (0.13-0.98) $95 \% \mathrm{Cl}, p=0.014]$. The change in body surface pain radiation immediately after exercise was [ -10.87 (from -17.51 to -4.22 ) $95 \% \mathrm{Cl}, p=0.003$ ] for high-intensity training and [-5.21 (from -9.40 to -1.03 ) $95 \% \mathrm{Cl}, p=0.019]$ for low-intensity training.

Conclusions: TrA training could increase the PPT of the waist core muscles and reduce the radiation range of waist pain. The benefits of high-intensity training are higher than those of low-intensity training.

Trial registration: ChiCTR-TRC-13003701. Registered 18 October 2013.

Code of ethical approval: 2018069.

Keywords: Transversus abdominis training, Chronic low Back pain, Pressure-pain threshold

\footnotetext{
*Correspondence: qiang897@163.com

${ }^{2}$ Department of Sport Rehabilitation, Shanghai University of Sport, Shanghai,

China

${ }^{4}$ Department of Rehabilitation Medicine, Shanghai Shangti Orthopaedic

Hospitai, Shanghai, China

Full list of author information is available at the end of the article
}

(c) The Author(s). 2021 Open Access This article is licensed under a Creative Commons Attribution 4.0 International License, which permits use, sharing, adaptation, distribution and reproduction in any medium or format, as long as you give appropriate credit to the original author(s) and the source, provide a link to the Creative Commons licence, and indicate if changes were made. The images or other third party material in this article are included in the article's Creative Commons licence, unless indicated otherwise in a credit line to the material. If material is not included in the article's Creative Commons licence and your intended use is not permitted by statutory regulation or exceeds the permitted use, you will need to obtain permission directly from the copyright holder. To view a copy of this licence, visit http://creativecommons.org/licenses/by/4.0/ The Creative Commons Public Domain Dedication waiver (http://creativecommons.org/publicdomain/zero/1.0/) applies to the data made available in this article, unless otherwise stated in a credit line to the data. 


\section{Introduction}

Low back pain (LBP) is one of the most common musculoskeletal disease in clinics, consuming a huge amount of medical resources over the years [1-4]. Nearly everyone has experienced LBP in their lives, and many people who have LBP could recover within 1 year, but some experiences chronic LBP (CLBP) with intermittence or persisting pain of low or medium intensity [1-3]. Thus, the management of symptoms, absenteeism, and decline in daily life activities results in substantial family and social financial losses. Moreover, many patients with CLBP suffer from pain and disability that affect their psychological, social, and physical conditions. These factors alter the pain-processing mechanisms [5-7]. In other words, the central pain-processing mechanisms of some patients who experience pain may become sensitive and exhibit increased neuronal responsiveness to injurious pain mechanism, and this situation results in a disproportionate number of pain complaints [8].

Long-term chronic symptoms could lead to changes in the central processing mechanisms at the neurophysiological level $[9,10]$. These changes promote the production of neural plasticity at the spinal cord for adaption to adverse changes, thus affecting psychological, somatosensory, and motor performances. Changes in somatosensory sensation, specifically changes in pressure pain threshold (PPT) and tissue hyperalgesia, occur in patients with CLBP, suggesting that central sensitization mechanisms may be involved [11]. Some researchers believed that persistent nociceptive stimulation is related to cortical and subcortical reorganization and that it plays an important role in the chronic process of LBP [6]. This potential change in somatosensory sensation may be determined by changes in tactile sensitivity caused by changes in the cerebral cortex and neurochemical changes in the process of central sensitization $[6,8-11]$. Common dyskinesia and poor treatment response in CLBP may be related to these neurophysiological changes [12].

Therapeutic training is currently the most commonly used treatment methods [13-17], and the use of a pressure biofeedback unit (PBU) for transversus abdominis muscle (TrA) training is one of the core muscle training methods [18-20]. However, some researchers believed that the intensities of activities of people with CLBP are not lower than those of asymptomatic people, and no evidence of direct correlation between the level of physical activity and pain intensity or dysfunction has been found [21]. Whether the effects of different intensities of transverse abdominal muscle training on people with CLBP in PPT is unclear [22]. The current study aimed to explore the effects of different intensities (sham training, low intensity, and high intensity) of transverse abdominal muscle training on people with CLBP in terms of PPT. The results could provide relevant theoretical basis for the clinical treatment of CLBP.

\section{Materials and methods}

Before this study, an experimental plan approved by the Ethics and Research Committee form Shanghai University of Sports (certificate number: 2018069) was formulated. The study was conducted in Shanghai University of Sports and Renji Hospital affiliated to Shanghai Jiaotong University School of Medicine from December 2018 to December 2019. Each subject signed an informed consent prior to entering the study. The specific experimental process is shown in Fig. 1.

\section{Subjects}

Through posters and online recruitment, a total of 45 patients with CLBP were recruited to participate in this experiment. Previous studies about PPT in CLBP were used as references when determining the sample size [23-25]. The effect size provided by Honoré $M$ [21] was chosen $(d=0.56$; 95\% CI: 00.4-1.08), the $\alpha$ err prod was 0.05 , the power (1- $\beta$ err prod) was 0.80 , the number of groups was three, the total sample size was 36 , and a $20 \%$ loss rate was considered. The final sample size was 45 (calculated by $\mathrm{G}^{*}$ Power 3.1.9.2 using $\mathrm{F}$ tests), considering that the difference of PPT has at least one standard deviation on average before and after training (95\% CIs and $80 \%$ predictive power). They were mainly recruited from the Rehabilitation Department of Renji Hospital, which is affiliated to the Shanghai Jiaotong University School of Medicine and Shanghai University of Sport.

The inclusion criteria were as follows: 1) age, 18-50 years; 2) having complaint about CLBP at least 3 months before the study and currently experiencing LBP; 3) visual analogue scale (VAS) score of $\geq 3$ when LBP occurs; 4) Roland Morris Disability Questionnaire score of $\geq 3$; 5) consent to refrain from drinking coffee, tea, milk tea, and other caffeinated drinks during the experiment; 6) no strenuous training a week before the experiment, and no behavior to change training habits; and 7) voluntary informed consent form and ability to complete the experiment. The age range was selected to provide a uniform sample of factors affecting CLBP in a general working population.

The exclusion criteria were as follows: 1) unable to evaluate pain intensity; 2) current use of analgesics, narcotics, or tobacco products; 3 ) history of previous surgery; 4) neurological diseases; 5) psychological illness or cognitive impairment; 6) pregnancy or preparation for pregnancy; 7) having pain in other parts of the body, including tennis elbow, knee-ankle joint pain, fracture, and cervical spondylosis; 8) other clear causes of LBP, such as spinal canal stenosis, ankylosing spondylitis, 


\section{CONSORT 2010 Flow Diagram}

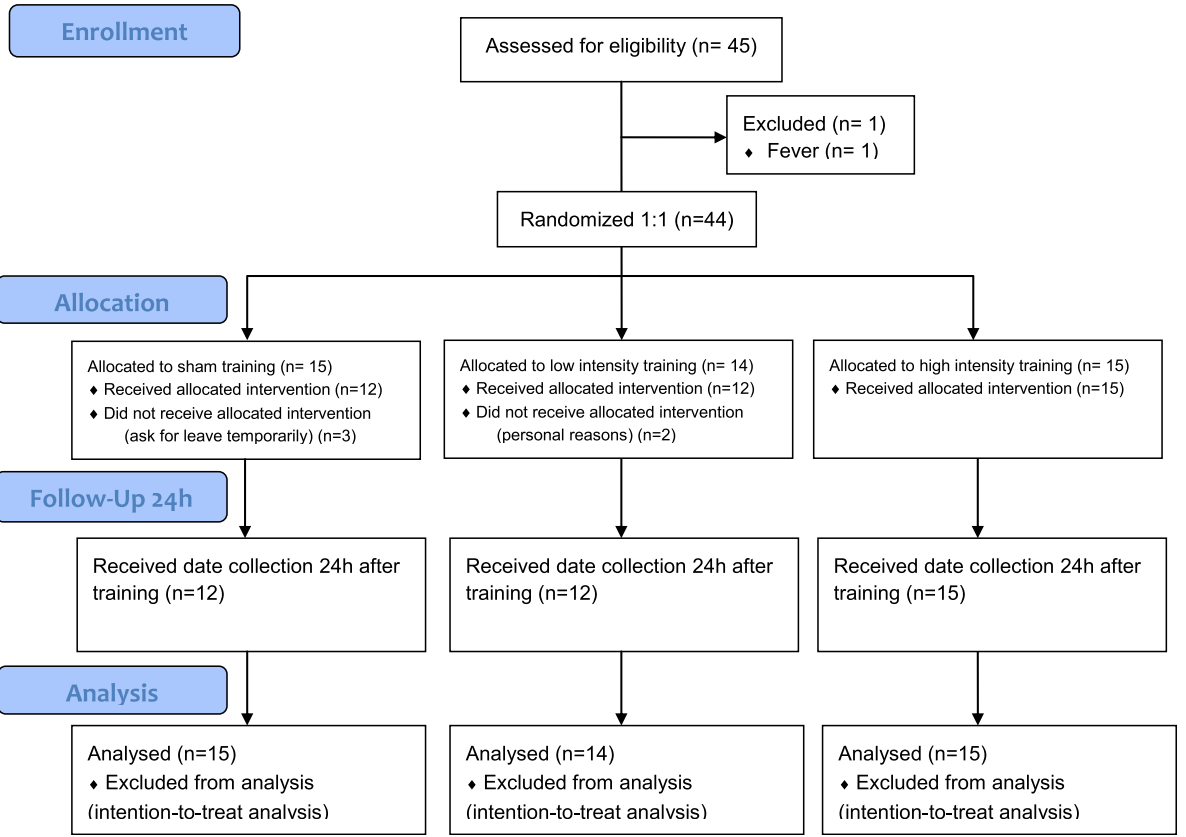

Fig. 1 Flowchart of the Training Experiment

intervertebral disc herniation, and sciatica; and 9) cold and fever.

The withdrawal criteria were as follows: 1) could not complete the training program in accordance with the process; 2) could not complete the trial for personal reasons; 3 ) exercises that break the daily routine, including occasional strenuous exercise; 4) seeing a doctor or taking other treatments for LBP; 5) and worsening of CLBP symptoms, such as increased pain or dysfunction.

\section{Procedure}

After the subjects passed the preliminary screening for recruitment, they were randomly selected. Then, baseline data were collected, mainly including demographic information, physical activity self-report questionnaire, PPT, body surface pain radiation range, and short-form McGill pain questionnaire. A series of transverse abdominal muscle training was performed at different intensities. The rating of perceived exertion (RPE), PPT, body surface pain radiation range, and short-form McGill pain questionnaire scores were collected immediately after training and $24 \mathrm{~h}$ after training. Statistical analyses were performed after all data were collected and archived.

All evaluators underwent systematic learning and training, and they were assisted by qualified physical therapists. The evaluators had no prior information about the purpose of the training. Evaluator 1 was responsible for collecting baseline data, evaluator 2 was responsible for training procedures, and evaluator 3 was responsible for collecting the PPT, short-form McGill pain questionnaire, and body surface pain radiation range. They were blinded to the experimental conditions. Each subject underwent separate training, and the data of each subject were collected separately. All subjects were instructed to refrain from discussing anything about the training. They were trained in designated rehabilitation centers.

\section{Training program}

PBU (Fig. 2) was used in the training of the transverse abdominal muscle. As a tool for core muscle training, PBU is widely used in the field of CLBP treatment, and it has good reliability and validity [26].

\section{Transversus abdominis muscle training}

The subjects laid on the treatment plane with knees bent, and the nose tip, sternum, and navel were aligned in a straight line. Their feet were flat on the treatment plane. The therapist instructed the subjects to inhale, exhale, and gently retract the navel towards the spine to indent the abdomen. Little or almost no movement of the pelvis was ensured, and the lower ribs were turned or pressed down. The chest was not sucked or lifted, and no increase in foot pressure was ensured, as shown in Fig. 3. The researchers touched the muscle at the intersection of the anterior superior iliac spine's horizontal line and the lateral rectus abdominis muscle, and the transverse abdominis muscle felt flat tension during 


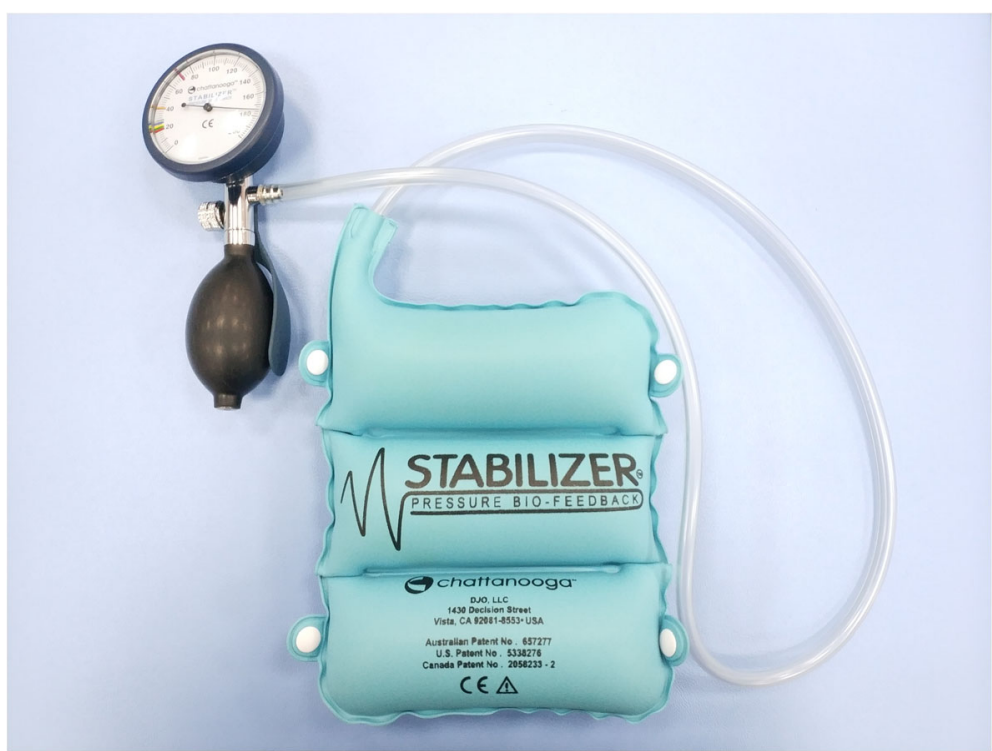

Fig. 2 Pressure Biofeedback Unit

contraction [27, 28] (muscle bulging could be felt by contraction of the transverse abdominis muscle), as shown in Fig. 4. The researchers provided the following instructions to the subjects: tighten navel stick to back, use back to press the air bag, let pointer reach a specified value, stabilize, tighten the buttocks, lift the anus, and prevent the pointer from floating. The researchers reminded the subjects to keep their spine stable during the transverse abdominis muscle training.

Before the training, the PBU was inflated to $40 \mathrm{mmHg}$. The experimenter completed air tightness check to ensure that the PBU was not leaking.

Before the formal training, the subjects were instructed to familiarize themselves with the training until they were able to complete the contraction training of the transverse abdominis. The entire training process was completed under the full guidance of the researchers for the subjects to be able to complete the training accurately and effectively.

\section{Different intensity training programs}

High-intensity group: the PBU pointer reached 180 $\mathrm{mmHg}$ or the subjects tried their best. The movements were performed for $15 \mathrm{~s}$ each, and the subjects rested for $5 \mathrm{~s}$ between the movements. The movement was performed 30 times, with a total of $10 \mathrm{~min}$.

Low-intensity group: the PBU pointer reached 100 $\mathrm{mmHg}$, and 15 movements were performed for $15 \mathrm{~s}$ each. A 5-s rest was performed between the movements, and the total time was $5 \mathrm{~min}$.

Sham training group: the subjects were instructed to lie on the treatment plane, as indicated in Fig. 3. All the procedures were the same as those in the high- and lowintensity groups, except that no contraction of the transverse abdominis muscle was performed. The researchers instructed the subjects to lie on the treatment plane without other movements to prevent the pointer from floating.

No difference was found between men and women in the different intensity training groups. A difference of $80 \mathrm{mmHg}$ between the high- and low-intensity groups was ensured to distinguish the training intensity effectively. Additional 15 movements were completed, and the training time was more than $5 \mathrm{~min}$. After the training was completed, each subject filled the RPE, which could effectively be used in distinguishing training intensity [29].

\section{Outcome measures}

The baseline data mainly collected were age, sex, height, weight, years of education, sedentary, regular training, duration of each training (minutes), weekly activity frequency, and self-perceived training intensity (0-6: 0 , rest; 1 , very weak; 2 , mild; 3 , medium; 4 , fatigue; and 5 , very tired).

First, baseline data were collected from the subjects, followed by PPT data by using a handheld pressure pain tester (FDX 25 FORCE GAGE $25 \times 0.02$ Ibf, Fig. 5) with a $1 \mathrm{~cm}^{2}$ replaceable rubber flat probe. The reliability of PPT measurement was acceptable [30], its intra- and intersessions were perfect with ICC $(0.85-0.99)$ [31, 32]. PPT was used to stimulate the corresponding muscles at a constant speed. Stimulation was immediately stopped when the subjects felt pain. Each measurement was repeated four times, and the average value was obtained. 


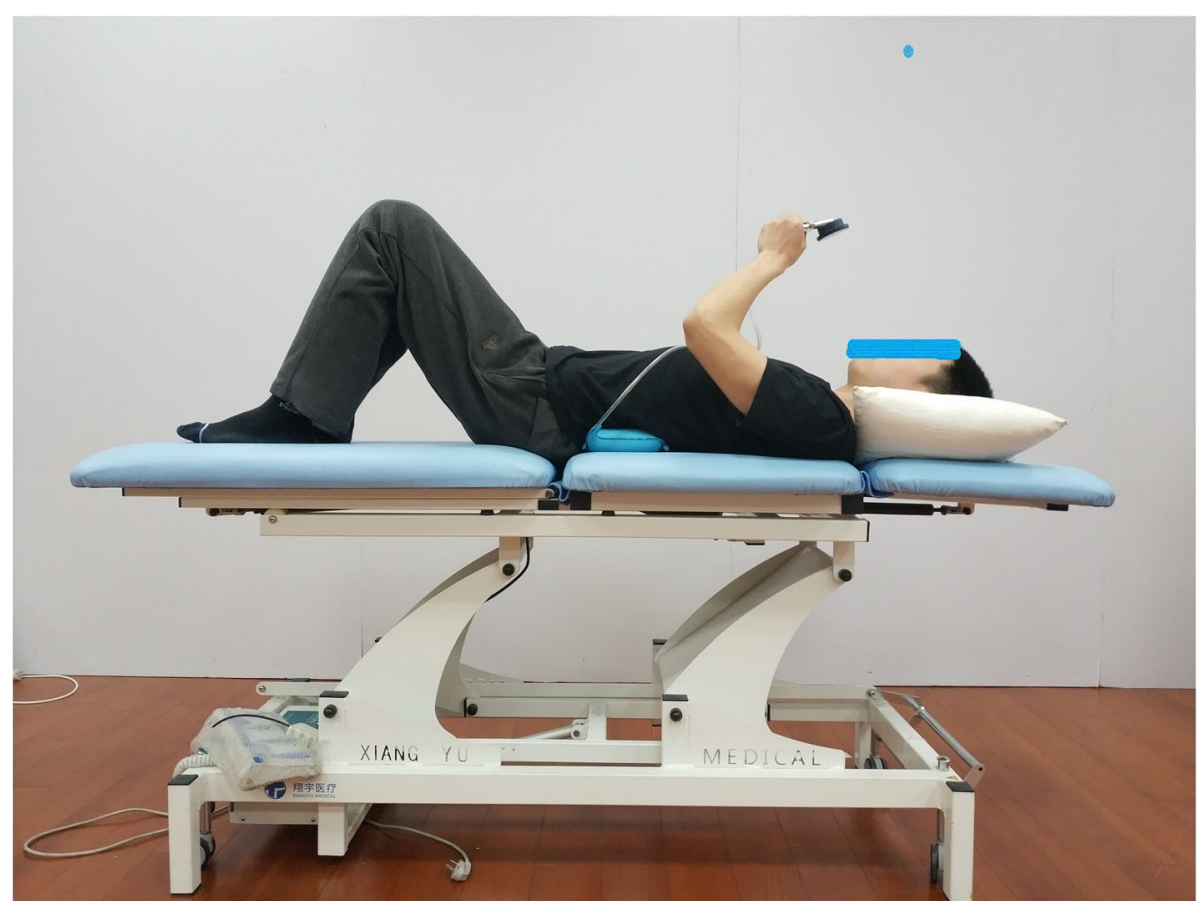

Fig. 3 Transversus Abdominis Muscle Training

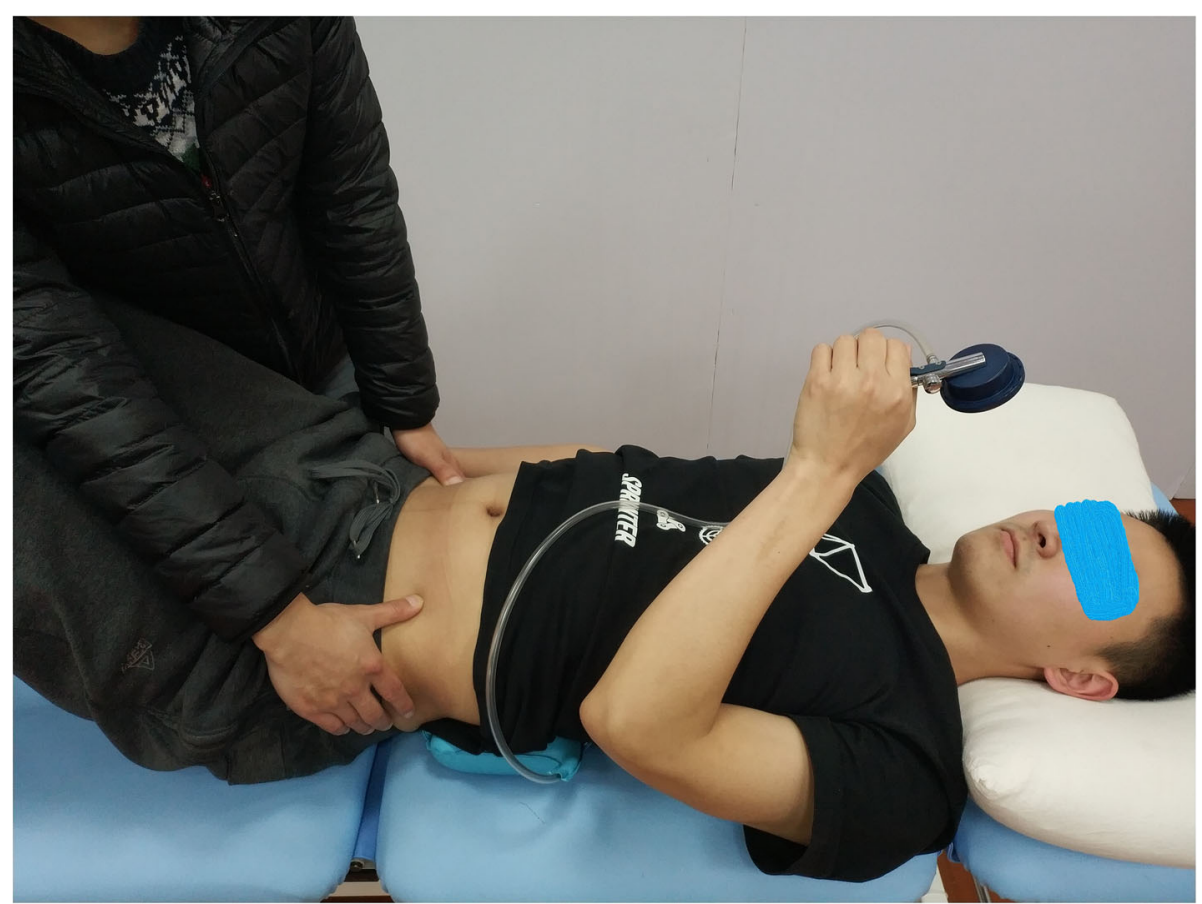

Fig. 4 Palpation 
After the subjects were familiarized with the test at their dominant arm, PPT was collected from the painful side. It was collected from the dominant side when the pain was in the middle area or symmetrical on both sides. As shown in Fig. 6, data from the following muscles were collected: levator scapula (two fingers above the upper scapula), rhomboid muscles (the midpoint of the connection between the scapular spine and third thoracic spinous process), iliopsoas muscle (the psoas major muscle next to the transverse process of the first lumbar vertebra), quadratus lumborum muscle (near the thick part of the iliopsoas muscle of the third lumbar spinous process), erector spinae (horizontal fifth lumbar vertebrae paraspinous), transversus abdominis (the intersection of the vertical line of the iliospinale posterior height and the horizontal line of the transverse process of the third lumbar vertebra), gluteus medius (the muscle depression below the posterior superior iliac spine), piriformis (The depression of the ischial foramen), hamstring muscle (the four fingers below the midpoint of the gluteal line), and gastrocnemius muscle (the place where the calf muscle is rich).

Data from the iliopsoas muscle, psoas muscle, vertical spine muscle, transverse abdominis muscle, gluteus medius muscle, and piriformis muscle were obtained because these muscles are common pain areas in patients with CLBP, and they are important core muscles for stable posture [33-35]. The levator scapulae and rhomboid muscles are proximal muscle reference points, whereas the hamstring and gastrocnemius muscles are distal muscle reference points. Both points were used in determining whether transverse abdominal muscle training has a central inhibitory and analgesic effect on CLBP.

Pain tolerance measurement involved $120 \%$ PPT continuous stimulation at the erector spinae measurement point for 1 minute [36]. During the test, the subjects were asked to pay attention to the nature of

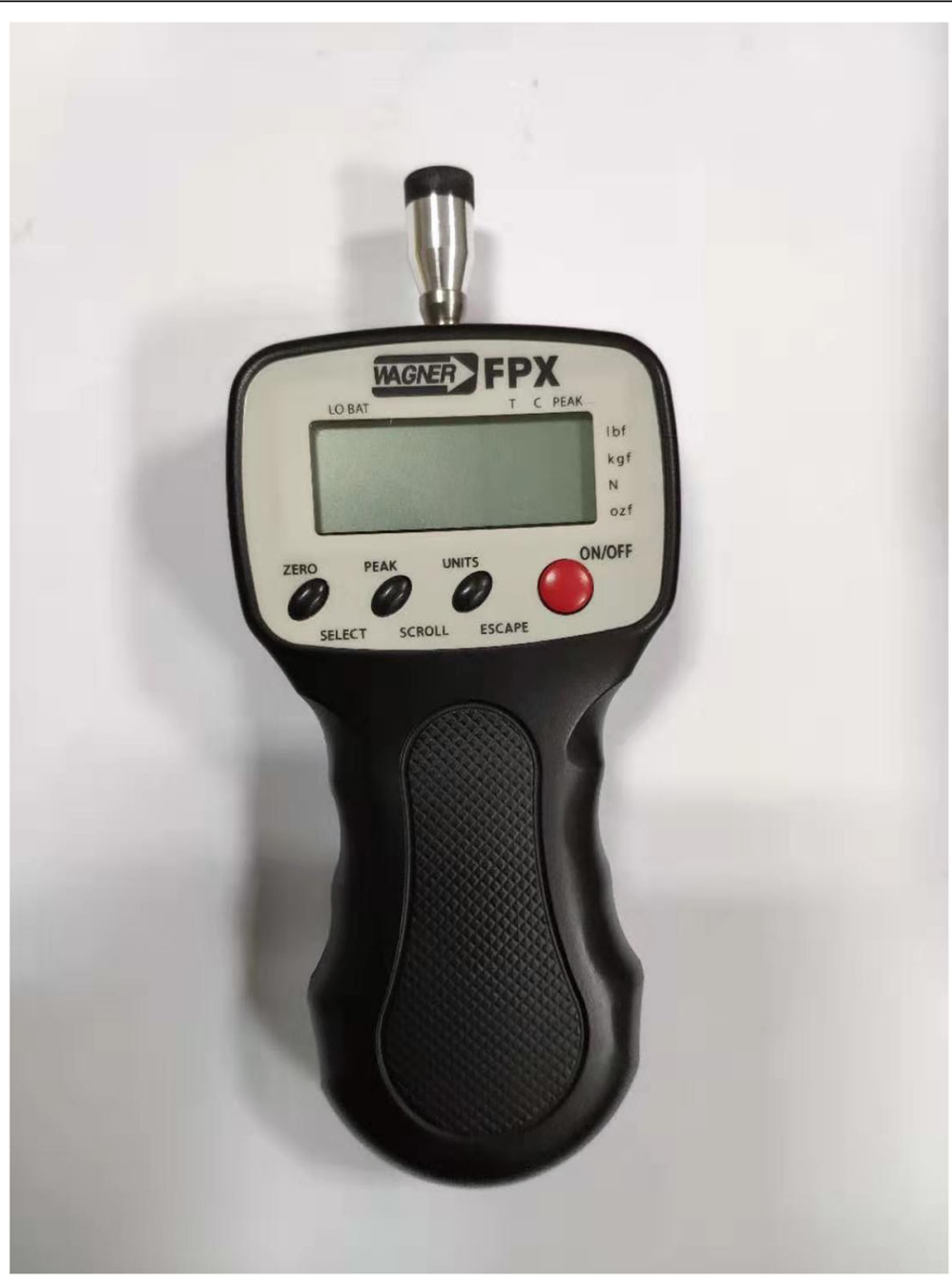

Fig. 5 Pressure-pain Threshold Texter 

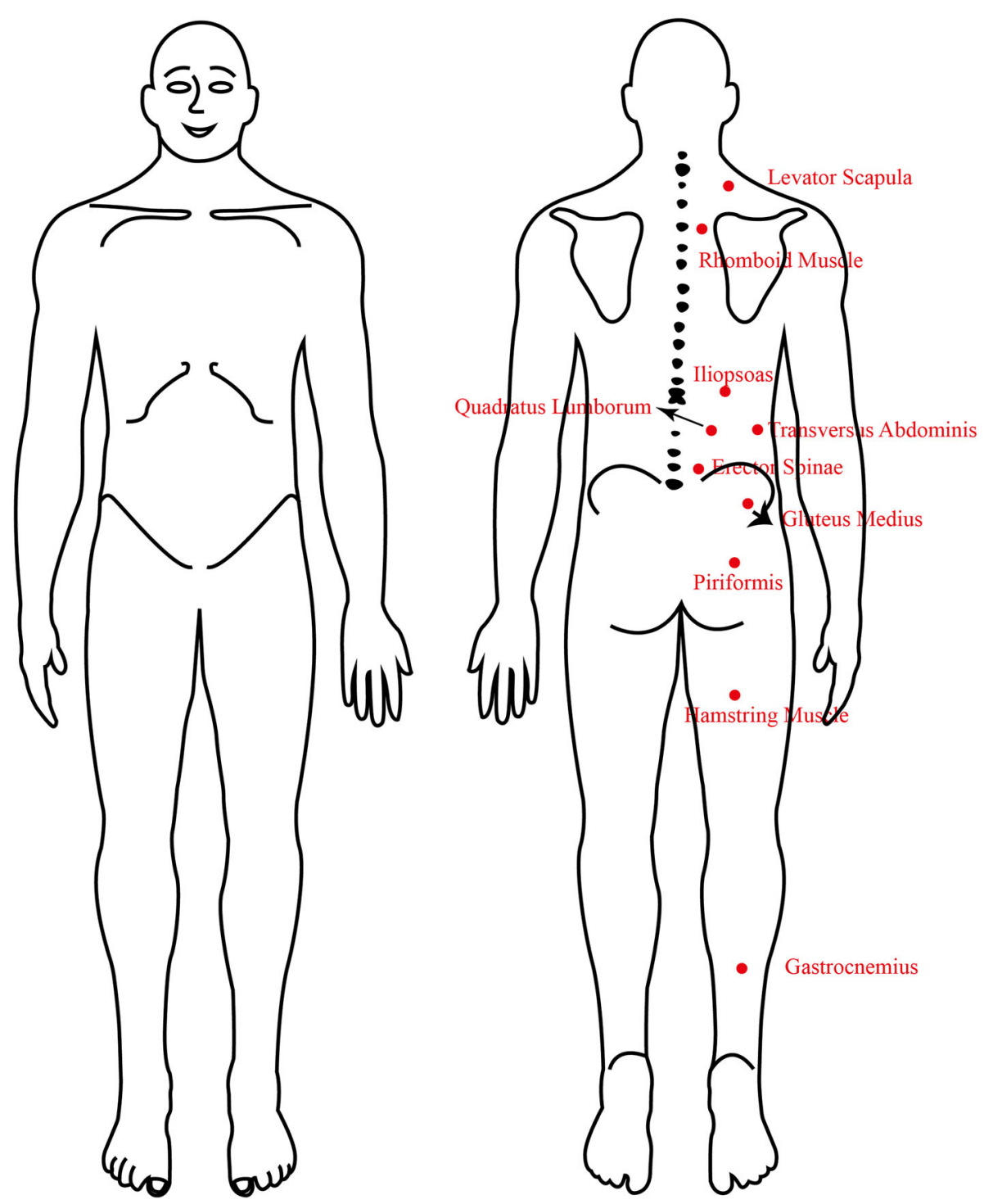

Fig. 6 Diagram of Muscle Test Points

the pain, pain range, and pain level. Then, they were asked to answer the figure of body surface pain radiation [37] (Fig. 7) and the short-form McGill pain questionnaire [36] immediately. The subjects were asked to circle the pain range on the figure of body surface pain radiation, and the data were evaluated in accordance with the number of grids circled by the subject. After the test was completed, the subjects were instructed not to train vigorously and to refrain from drinking caffeinated beverages, such as coffee and tea. The test was repeated after $24 \mathrm{~h}$.

\section{Statistical analysis}

Microsoft Excel 2019 was used in recording preliminary data, and IBM SPSS Statistics 20.0 was used for detailed statistical analysis after verification and classification.
Before statistical analysis was conducted, the ShapiroWilk test was used for initial testing of the data for normal distribution, and the data that did not conform to normal distribution were deleted. One-way ANOVA was performed to select the mean difference (post-intervention minus pre-intervention), and if no difference was found, no post-hoc analysis was performed. If a significant difference was found, a post-hoc analysis was performed. LSD was selected for post-hoc analysis. The results were expressed as mean \pm standard deviation $(\mathrm{M} \pm \mathrm{SD})$, and the corresponding $\mathrm{F}$ and $p$ values were marked. A $p$ value $<0.05$ was considered significant. Multiple paired $\mathrm{t}$-tests were used in analyzing differences within each group (pre, immediate, $24 \mathrm{~h}$ ). The correction family-wise error rate was adjusted to a $p$ value such as $0.05 / 2$ of comparisons. The results were expressed as 


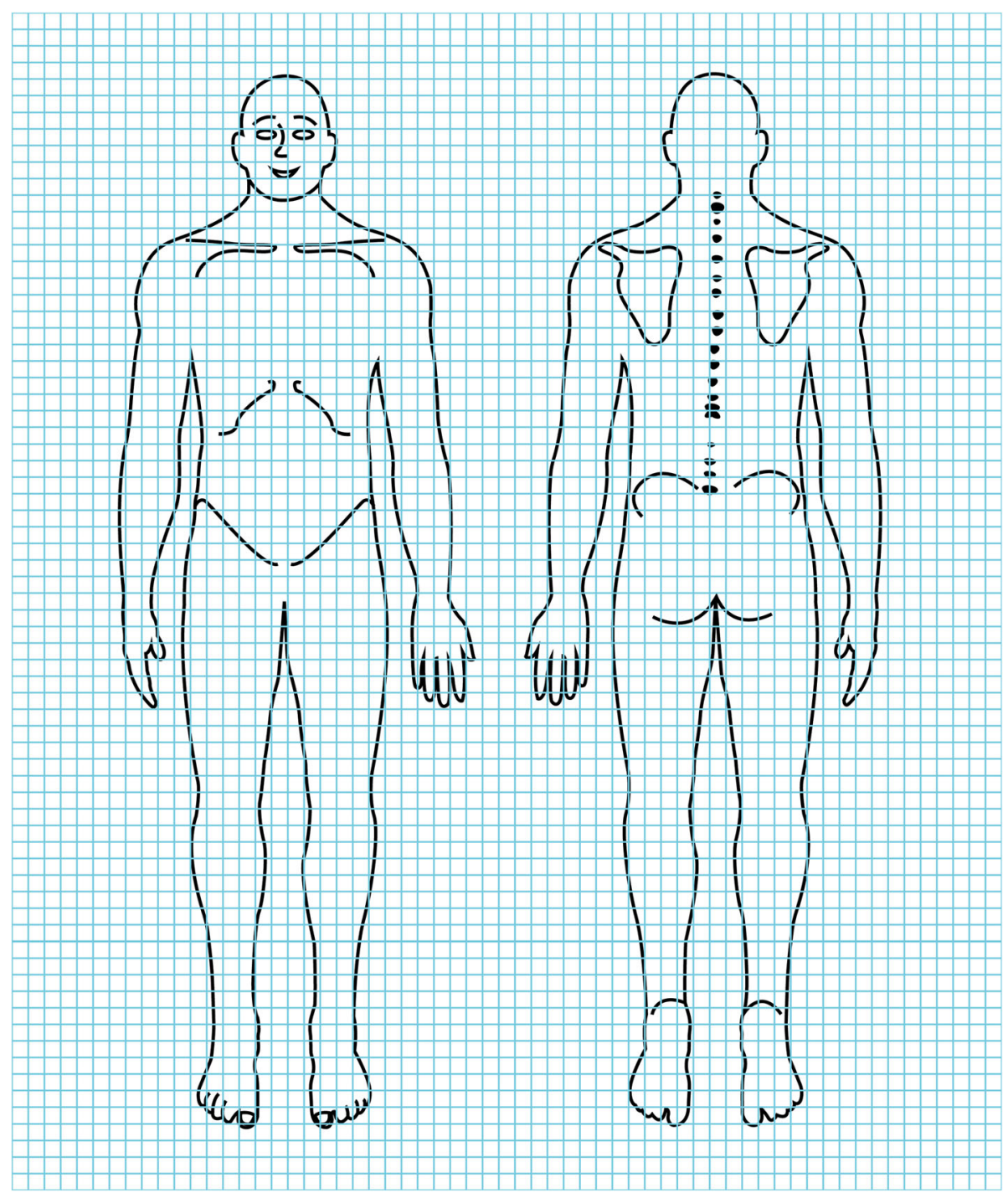

Fig. 7 Figure of Body Surface Pain Radiation

mean value and $95 \%$ confidence interval, and the corresponding $p$ value was marked.

Intention-to-treat analysis was used in subjects who completed baseline data collection but did not complete all tests or withdrew from the study. All subjects who completed randomization were included in the analysis, and the last data were used for statistical analysis.

\section{Results}

A total of 45 subjects were included in this study. One subject failed to complete the test performed on the following day because of fever, whereas the remaining 44 subjects completed all the experiments. A normal distribution test was performed before the data were analyzed. Three subjects in the sham training group did not receive allocated intervention (asked for temporary leave), and two subjects did not complete the training (withdrew for personal reasons). A total of 39 subjects received allocated intervention, 12, 12, and 15 of whom were in the sham training group, the low-intensity group, and the high-intensity group, respectively.

\section{Baseline data}

No significant difference in baseline data was observed among the three groups. Age group and gender were evenly distributed, and no significant differences in height, weight, and education years were observed. Likewise, no significant difference in daily activity training information (sedentary, regular training, duration of each training, activity frequency, and self-perception intensity) was observed among the subjects. The detailed statistics are shown in Table 1 . No significant differences were found in the baseline data of PPT and the short-form 
McGill pain questionnaire among the three groups, as detailed in Table 2.

\section{Effects of different training intensities}

The PPT of each group of muscles increased after the training, and the highest increase was observed in the high-intensity group. Significant improvement was noted in the area of pain radiation, and the highest degree of improvement was observed in the high-intensity group. The score in short-form McGill pain questionnaire's sensory item slightly increased, whereas that in emotion items decreased. Pain of the same intensity stimulated a slight increase in VAS. Other researchers notably reported similar findings, that is, patients with CLBP are prone to fatigue in the waist muscles and increase in such may be due to the sharpness of local muscle fatigue after the training task [38]. Details were shown in the stacking chart immediately after the training versus before training of the mean value at different training intensities (Fig. 8).

Immediately after the training, significant differences in the PPT of the TrA muscle $(\mathrm{F}=3.489, p=0.041)$, the body surface pain radiation $(\mathrm{F}=5.512, p=0.008)$, the present pain intensity $(\mathrm{F}=8.047, p=0.001)$, and VAS $(\mathrm{F}=3.534$, $p=0.038$ ) were noted between groups. Among them, a significant difference was found between the sham training group and high-intensity group in terms of PPT of the TrA muscles [ -0.56 (from -1.06 to -0.05 ), $p=0.046$ ], body surface pain radiation [9.93 (3.87-15.99), $p=0.002$, present pain intensity [0.73 $(0.30-1.17), p=0.001]$ and VAS [1.23 (0.29-2.18), $p=0.012]$. A significant difference between the low- and high-intensity groups was found in the present pain intensity [0.77 $(0.33-1.21), p=0.001]$. Further details are shown in Table 3.

No significant change was found in the sham training group. In the low-intensity group, the difference between immediately after training and before training was significant in the following: quadratus lumborum [0.61 (0.17-1.05), $p=0.009$ ], transverse abdominis [0.14 (from -0.15 to 0.43$), p=0.022$ ], and piriformis [0.55 (0.13$0.98), p=0.014]$. In the high-intensity group, the difference between immediately after training and before training was significant in the following: iliopsoas muscle [0.69 (0.13-1.25), $p=0.020]$, quadratus lumborum [0.84 $(0.23-1.45), p=0.012]$, erector spinae [0.66 $(0.18-1.15)$, $p=0.011]$, and transversus abdominis [0.70 (0.26-1.14), $p=0.004]$. Exactly $24 \mathrm{~h}$ after the training, only the highintensity group showed a significant difference in the quadratus lumborum [0.65 (0.14-1.17), $p=0.018]$. In terms of the body surface pain radiation range, both groups showed significant decreases as follows: lowintensity training immediately after training [ $[-5.21$ (from -9.40 to -1.03 ), $p=0.019$ ] and $24 \mathrm{~h}$ after the training [-7.29 (from -13.31 to -1.27 ), $p=0.021]$, high-intensity training immediately after the training [10.87 (from -17.51 to -4.22 ), $p=0.003$ ], and $24 \mathrm{~h}$ after the training [ -9.87 (from -16.43 to -3.31 ), $p=0.006$ ]. The improvement in the high-intensity group was higher than that in the low-intensity group. Further details are shown in Table 4.

\section{Discussion}

CLBP coexists with pain for a long time, and this state makes the perception of pain between patients with CLBP and normal people different $[39,40]$. The present study analyzed in detail the effects of TrA training on PPT and pain tolerance domain in patients with CLBP.

High-intensity training could significantly improve the body surface pain radiation of patients with CLBP and increase muscle PPT. Significant changes were found in the intra-group comparison of pain changes before and after training at different exercise intensities. The high-

Table 1 Baseline Data. Values are $(M \pm S D)$ unless stated otherwise

\begin{tabular}{|c|c|c|c|c|c|}
\hline & Sham Training $(n=15)$ & Low Intensity $(n=14)$ & High Intensity $(n=15)$ & $\mathbf{F}$ & $p$ \\
\hline Age/years & $22.53 \pm 2 . .03$ & $22.36 \pm 1.91$ & $22.73 \pm 2.79$ & 0.099 & 0.906 \\
\hline Male/n (\%) & $8(53.33)$ & $8(57.14)$ & $7(46.67)$ & 0.154 & 0.857 \\
\hline Female/n (\%) & $7(46.67)$ & $6(42.86)$ & $8(53.33)$ & & \\
\hline Height/cm & $170.93 \pm 6.02$ & $171.14 \pm 11.07$ & $169.27 \pm 9.38$ & 0.192 & 0.826 \\
\hline Weight/kg & $62.26 \pm 11.33$ & $65.00 \pm 12.62$ & $59.60 \pm 13.26$ & 0.684 & 0.510 \\
\hline Education/years $^{\mathrm{a}}$ & $4.73 \pm 1.53$ & $4.57 \pm 1.74$ & $4.40 \pm 1.84$ & 0.142 & 0.868 \\
\hline Sedentary/n (\%) & $10(66.67)$ & $9(64.28)$ & $8(53.33)$ & 0.301 & 0.742 \\
\hline Regular training/n (\%) & $10(66.67)$ & $9(64.28)$ & $10(66.67)$ & 0.011 & 0.989 \\
\hline Duration of each training/mins & $52.33 \pm 34.37$ & $65.71 \pm 36.52$ & $58.00 \pm 34.93$ & 0.524 & 0.595 \\
\hline Frequency/times per week & $3.33 \pm 1.79$ & $3.64 \pm 1.82$ & $3.00 \pm 1.65$ & 0.486 & 0.619 \\
\hline Self-perceived intensity ${ }^{b}$ & $2.60 \pm 1.18$ & $3.21 \pm 1.05$ & $2.73 \pm 1.10$ & 1.207 & 0.310 \\
\hline
\end{tabular}

a: Freshman was 1, sophomore was 2, junior year was 3, senior year was 4, first year of postgraduate was 5 , and so on

${ }^{\mathrm{b}}: 0-6$ points; 0 , rest; 1 , very weak; 2 , mild; 3 , medium; 4 , tiredness; 5 very tired 
Table 2 Baseline Data of Pressure-Pain Threshold and Short-form McGill Pain Questionnaire. M \pm SD Units: kgf.

\begin{tabular}{|c|c|c|c|c|c|}
\hline & Sham Training $(n=15)$ & Low Intensity $(n=14)$ & High Intensity $(n=15)$ & $F$ & $p$ \\
\hline Levator scapula & $3.92 \pm 1.53$ & $3.96 \pm 1.65$ & $4.03 \pm 1.57$ & 0.018 & 0.982 \\
\hline Rhomboid muscle & $4.64 \pm 1.72$ & $4.86 \pm 1.89$ & $4.52 \pm 1.67$ & 0.141 & 0.869 \\
\hline Iliopsoas & $5.29 \pm 2.00$ & $5.67 \pm 2.08$ & $4.95 \pm 1.92$ & 0.464 & 0.632 \\
\hline Quadratus lumborum & $5.76 \pm 2.07$ & $6.43 \pm 2.06$ & $6.15 \pm 2.19$ & 0.379 & 0.687 \\
\hline Erector spinae & $7.32 \pm 2.85$ & $7.60 \pm 2.40$ & $7.96 \pm 2.12$ & 0.252 & 0.778 \\
\hline Transversus abdominis & $5.75 \pm 2.00$ & $5.82 \pm 2.14$ & $5.60 \pm 2.24$ & 0.041 & 0.960 \\
\hline Gluteus medius & $6.47 \pm 2.01$ & $6.14 \pm 1.65$ & $5.99 \pm 1.55$ & 0.294 & 0.747 \\
\hline Piriformis & $6.73 \pm 2.01$ & $6.80 \pm 1.67$ & $6.26 \pm 1.90$ & 0.314 & 0.732 \\
\hline Hamstring muscle & $7.12 \pm 2.69$ & $7.00 \pm 2.10$ & $5.85 \pm 2.25$ & 1.296 & 0.285 \\
\hline Gastrocnemius & $5.28 \pm 1.56$ & $5.78 \pm 1.29$ & $4.96 \pm 1.48$ & 1.181 & 0.317 \\
\hline Body surface pain radiation & $6.80 \pm 8.22$ & $18.57 \pm 21.02$ & $17.00 \pm 11.13$ & 2.932 & 0.065 \\
\hline \multicolumn{6}{|c|}{ Short-form McGill Pain Questionnaire ${ }^{a}$} \\
\hline Sensory items & $4.87 \pm 2.16$ & $5.45 \pm 3.01$ & $5.80 \pm 3.75$ & 1.122 & 0.579 \\
\hline Emotion items & $1.27 \pm 1.22$ & $2.29 \pm 2.89$ & $1.20 \pm 1.57$ & 1.324 & 0.277 \\
\hline VAS $^{b}$ & $4.63 \pm 2.78$ & $5.46 \pm 2.00$ & $4.20 \pm 2.21$ & 1.065 & 0.354 \\
\hline Present pain intensity ${ }^{c}$ & $0.73 \pm 0.70$ & $0.71 \pm 0.61$ & $1.00 \pm 0.85$ & 0.710 & 0.497 \\
\hline
\end{tabular}

${ }^{a}$ :Assessed pain during 120\% PPT stimulation; ${ }^{b}$ : Pain score at 120\% PPT stimulation for $60 \mathrm{~s}^{c}{ }^{c}$ : Pain score at the erector spinae stimulation point 1 min after the pain tolerance threshold was measured

intensity group had more significant differences than the low-intensity group, while the sham training group had no significant difference. Figure 8 shows a slight change in the sham training group, indicating a certain placebo effect. The muscles that changed in the group were mainly iliopsoas, quadratus lumborum, erector spinae, and $\operatorname{TrA}$, indicating that the use of PBU to train $\operatorname{TrA}$ was effective in training the corresponding core muscle groups. Body surface pain radiation showed a significant reduction. After the training, the average values of the subjects' present pain intensity, VAS, and sensory items scores increased slightly, indicating that the number of neurons that could be recruited from the waist increased after TrA training and PPT could be stimulated accurately. Significant differences were found between the sham training group and the high-intensity group in terms of TrA's PPT, body surface pain radiation area, present pain intensity, and VAS. The above data showed

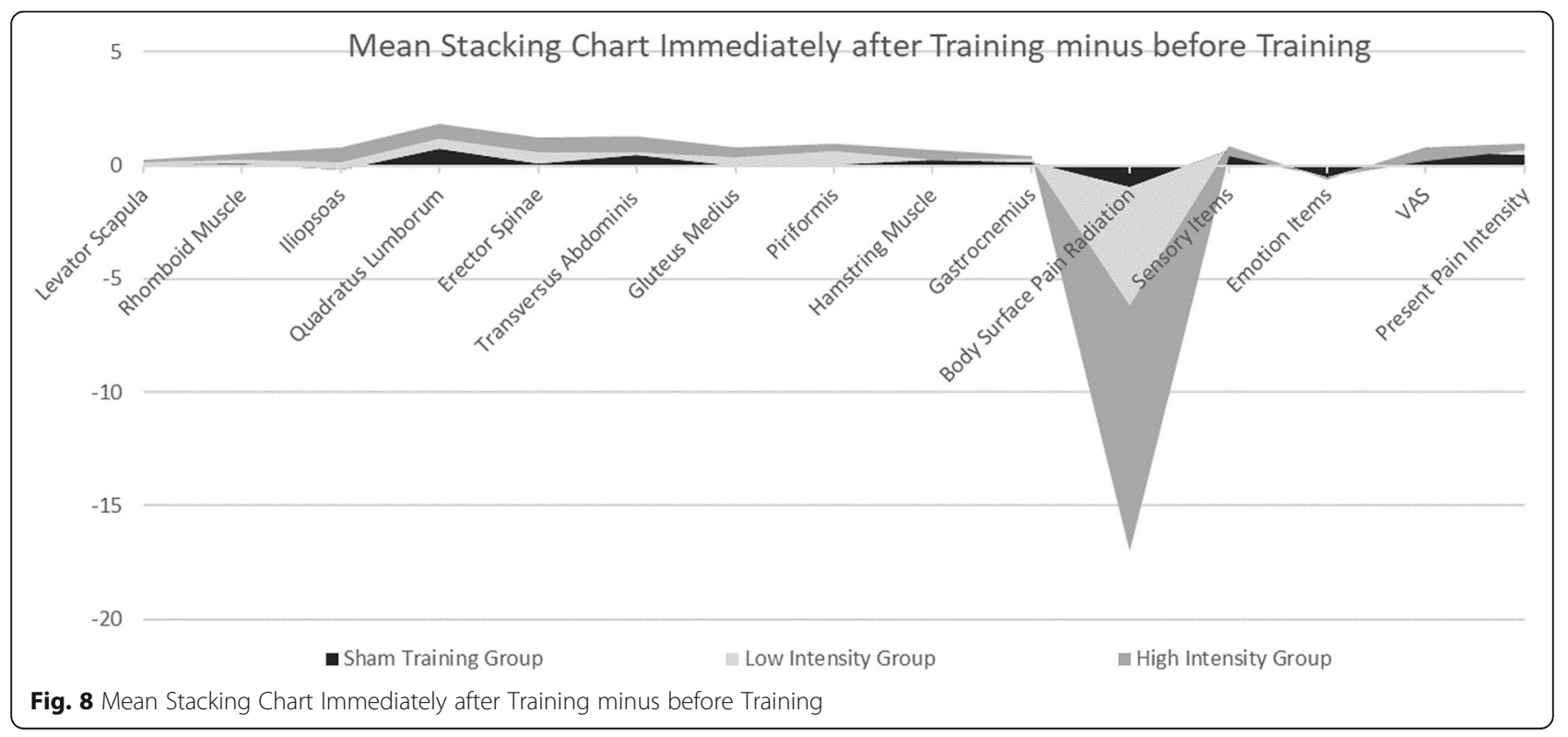


Table 3 Items with Significant Differences in Pressure-Pain Threshold before and Immediately after Training between Each Group ${ }^{a}$

\begin{tabular}{|c|c|c|c|c|c|c|c|c|}
\hline \multirow[t]{2}{*}{ Variable } & \multirow{2}{*}{$\begin{array}{l}\text { Sham } \\
\text { training } \\
n=15\end{array}$} & \multirow{2}{*}{$\begin{array}{l}\text { Low intensity } \\
n=14\end{array}$} & \multirow{2}{*}{$\begin{array}{l}\text { High intensity } \\
n=15\end{array}$} & \multirow[t]{2}{*}{$\mathrm{F}$} & \multirow[t]{2}{*}{$p$} & \multicolumn{3}{|c|}{ Mean between-group difference } \\
\hline & & & & & & $\begin{array}{l}\text { Sham training vs. } \\
\text { low intensity }\end{array}$ & $\begin{array}{l}\text { Sham training vs. } \\
\text { high intensity }\end{array}$ & $\begin{array}{l}\text { Low intensity vs. } \\
\text { high intensity }\end{array}$ \\
\hline \multicolumn{9}{|l|}{ Transversus abdominis } \\
\hline $\begin{array}{l}\text { Baseline mean } \\
\text { (SD) }\end{array}$ & $5.75(2.00)$ & $5.82(2.14)$ & $5.60(2.24)$ & - & - & - & - & - \\
\hline Mean score (SD) & $6.20(1.85)$ & $5.97(2.07)$ & $6.30(2.01)$ & - & - & - & - & - \\
\hline $\begin{array}{l}\text { Mean change from } \\
\text { baseline }(95 \% \mathrm{Cl})\end{array}$ & $\begin{array}{l}0.45 \\
(0.70 \text { to } 0.83)\end{array}$ & $\begin{array}{l}0.14 \\
(-0.15 \text { to } 0.43)\end{array}$ & $\begin{array}{l}0.70(0.25 \text { to } \\
1.14)\end{array}$ & 3.489 & 0.041 & $\begin{array}{l}0.31 \\
(-0.19 \text { to } 8.17)\end{array}$ & $\begin{array}{l}-0.56 \\
(-1.06 \text { to }-0.05)^{b}\end{array}$ & $\begin{array}{l}-0.24 \\
(-0.74 \text { to } 0.25)\end{array}$ \\
\hline \multicolumn{9}{|c|}{ Body surface pain radiation } \\
\hline $\begin{array}{l}\text { Baseline mean } \\
\text { (SD) }\end{array}$ & $6.80(8.22)$ & $18.57(21.02)$ & $17.00(11.13)$ & - & - & - & - & - \\
\hline Mean score (SD) & $5.87(7.18)$ & $13.36(15.66)$ & $6.13(4.61)$ & - & - & - & - & - \\
\hline $\begin{array}{l}\text { Mean change from } \\
\text { baseline }(95 \% \mathrm{Cl})\end{array}$ & $\begin{array}{l}-0.93 \\
(-2.16 \text { to } 0.30)\end{array}$ & $\begin{array}{l}-5.21 \\
(-9.40 \text { to }-1.03)\end{array}$ & $\begin{array}{l}-10.87 \\
(-17.51 \text { to }-4.22)\end{array}$ & 5.512 & 0.008 & $\begin{array}{l}4.28 \\
(-1.89 \text { to } 10.45)\end{array}$ & $\begin{array}{l}9.93 \\
(3.87 \text { to } 15.99)^{b}\end{array}$ & $\begin{array}{l}5.65 \\
(-0.52 \text { to } 11.82)\end{array}$ \\
\hline \multicolumn{9}{|l|}{ Present pain intensity } \\
\hline $\begin{array}{l}\text { Baseline mean } \\
\text { (SD) }\end{array}$ & $0.73(0.70)$ & $0.71(0.61)$ & $1.00(0.85)$ & - & - & - & - & - \\
\hline Mean score (SD) & $1.20(0.78)$ & $1.21(0.98)$ & $0.73(0.59)$ & - & - & - & - & - \\
\hline $\begin{array}{l}\text { Mean change from } \\
\text { baseline }(95 \% \mathrm{Cl})\end{array}$ & $\begin{array}{l}0.47 \\
(0.18 \text { to } 0.75)\end{array}$ & $\begin{array}{l}0.50 \\
(0.06 \text { to } 0.94)\end{array}$ & $\begin{array}{l}-0.27 \\
(-0.52 \text { to }-0.01)\end{array}$ & 8.047 & 0.001 & $\begin{array}{l}-0.03 \\
(-0.47 \text { to } 0.41)\end{array}$ & $0.73(0.30 \text { to } 1.17)^{\mathrm{b}}$ & $\begin{array}{l}0.77 \\
(0.33 \text { to } 1.21)^{b}\end{array}$ \\
\hline \multicolumn{9}{|l|}{ Visual analogue scale } \\
\hline $\begin{array}{l}\text { Baseline mean } \\
\text { (SD) }\end{array}$ & $4.63(2.78)$ & $5.46(2.00)$ & $4.20(2.21)$ & - & - & - & - & - \\
\hline Mean score (SD) & $5.20(2.48)$ & $5.64(1.64)$ & $3.67(1.88)$ & - & - & - & - & - \\
\hline $\begin{array}{l}\text { Mean change from } \\
\text { baseline }(95 \% \mathrm{Cl})\end{array}$ & $\begin{array}{l}0.57 \\
(-0.19 \text { to } 1.33)\end{array}$ & $\begin{array}{l}0.18 \\
(-0.46 \text { to } 0.82)\end{array}$ & $\begin{array}{l}-0.53 \\
(-1.34 \text { to } 0.27)\end{array}$ & 3.534 & 0.038 & $\begin{array}{l}0.46(-0.51 \text { to } \\
1.42)\end{array}$ & $1.23(0.29 \text { to } 2.18)^{b}$ & $\begin{array}{l}0.78(-0.19 \text { to } \\
1.74)\end{array}$ \\
\hline
\end{tabular}

a Data analysis was performed by 1-way ANOVA, select LSD for post-hoc analysis

${ }^{b}$ The significance level of the mean difference is 0.05

Table 4 Items with Significant Differences in Pressure-pain Threshold before and after Training in Each Group*. Units: kgf

\begin{tabular}{|c|c|c|c|c|c|}
\hline & & Immediately after training & & $24 \mathrm{~h}$ after training & \\
\hline Group & Item & $-\mathrm{X}(95 \% \mathrm{Cl})$ & $p$ & ${ }^{-} \mathrm{X}(95 \% \mathrm{Cl})$ & $P$ \\
\hline Sham training & - & - & - & - & - \\
\hline \multirow[t]{4}{*}{ Low intensity } & Quadratus lumborum & $0.61(0.17-1.05)$ & 0.009 & - & - \\
\hline & Transversus abdominis & $0.14(-0.15-0.43)$ & 0.022 & - & - \\
\hline & Piriformis & $0.55(0.13-0.98)$ & 0.014 & - & - \\
\hline & Body surface pain radiation ${ }^{a}$ & -5.21 (from -9.40 to -1.03 ) & 0.019 & $-7.29(-13.31$ to -1.27$)$ & 0.021 \\
\hline \multirow[t]{5}{*}{ High intensity } & Iliopsoas & $0.69(0.13-1.25)$ & 0.020 & - & - \\
\hline & Quadratus lumborum & $0.84(0.23-1.45)$ & 0.012 & $0.65(0.14-1.17)$ & 0.018 \\
\hline & Erector spinae & $0.66(0.18-1.15)$ & 0.011 & - & - \\
\hline & Transversus abdominis & $0.70(0.26-1.14)$ & 0.004 & - & - \\
\hline & Body surface pain radiation ${ }^{a}$ & -10.87 (from -17.51 to -4.22 ) & 0.003 & -9.87 (from -16.43 to -3.31 ) & 0.006 \\
\hline
\end{tabular}

*: The correction family-wise error rate was done by adjusted $p$-value $0.05 / 2$. "-" Data with no significant difference is not displayed in the Table 4

${ }^{a}$ : Items of the Short-form McGill Pain Questionnaire 
that $\operatorname{TrA}$ training is an reliable core muscle training method that could simply and effectively stimulate related core muscles.

In the experimental preparation phase, some subjects may compensate when they perform high-intensity training compared with low-intensity training. Therefore, during the familiarization phase of the subject, the experimenter should ensure that the subject mastered the transverse abdominis training without compensation. When performing high-intensity training, the experimenter should accurately palpate, remind the subject to keep the spine stable, and ensure that the transverse abdominis could be accurately trained. No subject reported muscle soreness in this experiment, and this situation requires attention in the next experiment.

The stability and coordination of the lumbar core muscles is an important condition for maintaining the stability of the lumbar spine. TrA training could effectively activate the core muscles, correct poor postures and maintain the stability of the lumbar spine, thus improving the PPT of patients with CLBP $[20,41]$ Grooms $\mathrm{DR}$ [20] used PBU to train the transverse abdominal muscles of patients with LBP and pointed out that this training method has good sensitivity and moderate specificity. França FR [41] revealed that training of the transverse abdominal muscles could effectively relieve pain in patients with LBP, alleviate disability, and improve quality of life. Park KN [42] studied the use of PBU in TrA training during active prone knee flexion and found that TrA training could effectively adjust the strength of the waist and abdomen core muscles, thereby improving their coordination and stability, enhancing the control and correction of the pelvis position, and reducing waist pain. Von Garnier K [43] used PBU to measure the recruitment test of transverse abdominis muscles and mentioned that during deep core muscle training, the other core muscles of the waist and abdomen have obvious coordinated contraction. In a study of $\mathrm{P}$ Hodges [28] and C Richardson [27], subjects were asked to contract the pelvic floor muscles and gluteal muscles by tightening the levator anus and buttocks during the transverse abdominis training. The results showed improved training effects. Cynn HS [44] used PBU for lumbar stability training and detected the surface electromyography signals of the quadratus lumborum, gluteus medius, TrA, external oblique, rectus abdominis, and multifidus muscle contractions. The present study obtained similar results. After TrA training, the tenderness threshold of other the waist core muscle groups changed because the muscles worked together. The pain areas of the reference muscles, namely, the levator scapula, rhomboid, hamstring, and gastrocnemius muscles, showed no notable changes, and no central nervous system inhibition of pain was observed. The possible reason is the low intensity and duration of the task. Changes in areas farther from the training area occurred after excessive or strenuous exercise [38]. This finding suggested that training intensity could be further increase for good results.

A study comparing subjects with acute and chronic LBP and with PPT [45] showed that those with CLBP had extensive pressure hyperalgesia in the waist area, whereas the those with acute LBP did not have this condition. Similarly, a similar phenomenon was noted in the present study. Patients with CLBP were more prone to generalized radiation and had longer residual time than those with acute LBP. This phenomenon may have been caused by long-term pain experienced by patients with CLBP; this condition indicated that the central nervous and peripheral sensory systems underwent adaptive changes $[45,46]$. Hennings A [47] studied the effect of physical activity on the pain areas of patients with multiple physical symptoms and found that short-term low-intensity exercise could increase PPT and reduce pain. Moreover, the level of physical activity is a related covariate. The stronger the level of physical activity is, the greater the change in the pain area. In the present research, highintensity training could improve PPT more effectively in CLBP than low-intensity training. In a prospective study of Gupta A [48], a decrease in PPT and an increase in tender points were found to be the predictors of chronic generalized pain. Low PPT may be the result of pain and related factors. McPhee ME [49] found that as the duration of pain experienced by patients with LBP increased, their PPT decreased, and the residual pain caused by external stimulation lasted longer. The experiments in the present study showed that transverse abdominal muscle training could reduce the radiation range of waist pain and increase PPT, thus providing new evidence of the effectiveness of core muscle training in treating CLBP.

Some researchers [50] pointed out that the CLBP population may have different degrees of core muscle strength impairment. Targeted exercise training could improve the coordination and recruitment rate of the core muscles that support the spine, thereby improving the coordination and stability of the spine. Specialized TrA training for patients with CLBP could effectively increase the recruitment rate of $\operatorname{TrA}(7.8 \%)$, which is better than that of ordinary exercise (4.9\%) and spinal manipulation therapy (3.7\%). A significant medium correlation was also found between the improvement of the recruitment rate of $\operatorname{TrA}$ and the reduction in pain and dysfunction $(\mathrm{r}=-0.35 ; 95 \%$ CI $0.02-0.62)$ [51]. Some scholars $[52,53]$ pointed out a delay in the feedforward activation of transversus abdominis in a population with CLBP. Targeted muscle training could improve 
feedforward postural strategies, and the magnitude of its effect depends on the type and quality of sports training. The experiment in the present study confirmed the results of previous studies.

After TrA training, the blood circulation of the waist core muscles is accelerated, which could promote the absorption of pain inflammatory factors [54]. After the pain is reduced, it could promote improvement of waist proprioception [55]. Studies showed that even a small amount of exercise may cause changes in the cerebral cortex and increase motor evoked potentials [56]. Increased training may promote functional reorganization of the somatosensory cortex [57]. The plasticity of the brain facilitates exercise learning and improves daily lumbar and pelvic spine control without pain [58]. Changes in other peripheral substances such as betaendorphin, may be one of the physiological mechanisms of TrA training analgesia. Studies have shown that medium to high-intensity core muscle training for patients with chronic pain may promote the release of endogenous opioids, cause endogenous analgesia and improve PPT $[59,60]$. This phenomenon is a virtuous circle, and core muscle training is its beginning [61].

\section{Conclusion}

Transversus abdominis training could increase the PPT of the waist core muscles of patients with CLBP and reduce the radiation range of pain. High-intensity training could activate more waist core muscles and has more benefits than low-intensity training. The most obvious improvement in body surface pain radiation was observed after high-intensity training. This result is of great importance to the formulation of exercise prescriptions for patients with CLBP, and it provides references for major guidelines in listing exercise as the main treatment for CLBP.

However, the sample size of this study is relatively small, and the age group of the subjects is relatively concentrated. Follow-up studies should consider further increasing the sample size to make the research results representative. In addition, long-term intervention study was not conducted, and the effect of long-term intervention on PPT is unclear. These problems could be addressed in the follow-up study.

\section{Acknowledgements}

The authors (CM.X, ZW. F, and XQ.W) gratefully acknowledge the Fok YingTong Education Foundation of China (161092), the Scientific and Technological Research Program of the Shanghai Science and Technology Committee (Fund number: 19080503100), and the Shanghai Key Lab of Human Performance (Shanghai University of Sport; fund number: 11DZ2261100).

\section{Authors' contributions}

Concept/idea/research design: Changming Xu, Xueqiang Wang. Writing: Changming Xu, Zhiwei Fu. Date collection: Zhiwei Fu. Date analysis: Zhiwei Fu. Project management: Changming Xu. Consultation (including review of manuscript before submission): Xueqiang Wang. The author(s) read and approved the final manuscript.

\section{Funding}

The author(s) disclosed receipt of financial support from the following for the research, authorship and/or publication of this article: National Key R\&D Program of China (2018YFC1314700), Fok Ying-Tong Education Foundation of China (fund number: 161092), the Scientific and Technological Research Program of the Shanghai Science and Technology Committee (fund number: 19080503100), and the Shanghai Key Lab of Human Performance (Shanghai University of Sport, fund number: 11DZ2261100)

\section{Availability of data and materials}

The datasets generated and analyzed in this study are not available because the entire research under these funds has not been openly published yet, and this paper is one of the subtopics. However, they are available from the corresponding author upon reasonable request.

\section{Declarations}

\section{Ethics approval and consent to participate}

This research was approved by the Ethics Committee of Shanghai University of Sport. Participants were informed of the experimental procedures and risks, and they provided a written informed consent prior to attending several familiarization sessions. All methods were carried out in accordance with relevant guidelines and regulations.

\section{Consent for publication}

Written informed consent for publication was obtained from all participants.

\section{Competing interests}

The author(s) declared no potential conflicts of interest with respect to the research, authorship, and/or publication of this article.

\section{Author details}

${ }^{1}$ Department of Rehabilitation, Renji Hospital Affiliated to Shanghai Jiaotong University School of Medicine, Shanghai, China. ${ }^{2}$ Department of Sport Rehabilitation, Shanghai University of Sport, Shanghai, China. ${ }^{3}$ Department of Bone and Joint Surgery, Renji Hospital Affiliated to Shanghai Jiaotong University School of Medicine, Shanghai, China. ${ }^{4}$ Department of Rehabilitation Medicine, Shanghai Shangti Orthopaedic Hospitai, Shanghai, China.

Received: 23 December 2020 Accepted: 23 March 2021

Published online: 01 April 2021

\section{References}

1. Vlaeyen JWS, Maher CG, Wiech K, van Zundert J, Meloto CB, Diatchenko L, et al. Low back pain (primer). Nature Reviews: Disease Primers. 2018;4(1):52. https://doi.org/10.1038/s41572-018-0052-1.

2. Buchbinder R, van Tulder M, Öberg B, Costa LM, Woolf A, Schoene M, et al. Low back pain: a call for action. Lancet. 2018;391(10137):2384-8. https://doi. org/10.1016/s0140-6736(18)30488-4.

3. Clark S, Horton R. Low back pain: a major global challenge. Lancet. 2018; 391(10137):2302. https://doi.org/10.1016/s0140-6736(18)30725-6

4. Linek P, Noormohammadpour P, Mansournia MA, Wolny T, Sikora D. Morphological changes of the lateral abdominal muscles in adolescent soccer players with low back pain: a prospective cohort study. J Sport Health Sci. 2020;9(6):614-9. https://doi.org/10.1016/j. jshs.2018.02.002.

5. Clauw DJ. Diagnosing and treating chronic musculoskeletal pain based on the underlying mechanism (s). Best Pract Res Clin Rheumatol. 2015;29(1):619. https://doi.org/10.1016/j.berh.2015.04.024.

6. Roussel NA, Nijs J, Meeus M, Mylius V, Fayt C, Oostendorp R. Central sensitization and altered central pain processing in chronic low back pain: fact or myth? Clin J Pain. 2013;29(7):625-38. https://doi.org/10.1097/AJP. Ob013e31826f9a71.

7. Steele JR, Coltman CE, McGhee DE. Effects of obesity on breast size, thoracic spine structure and function, upper torso musculoskeletal pain and physical activity in women. J Sport Health Sci. 2020;9(2):140-8. https://doi.org/10.101 6/j.jshs.2019.05.003. 
8. Nijs J, Meeus M, Van Oosterwijck J, et al. Treatment of central sensitization in patients with 'unexplained'chronic pain: what options do we have? Expert Opin Pharmacother. 2011;12(7):1087-98. https://doi.org/10.1517/14 656566.2011.547475.

9. Hashmi JA, Baliki MN, Huang L, Baria AT, Torbey S, Hermann KM, et al. Shape shifting pain: chronification of back pain shifts brain representation from nociceptive to emotional circuits. Brain. 2013;136(9):2751-68. https:// doi.org/10.1093/brain/awt211.

10. Zusman M. Forebrain-mediated sensitization of central pain pathways:'nonspecific'pain and a new image for MT. Man Ther. 2002;7(2):80-8. https://doi. org/10.1054/math.2002.0442.

11. Meints SM, Mawla I, Napadow V, Kong J, Gerber J, Chan ST, et al. The relationship between catastrophizing and altered pain sensitivity in patients with chronic low back pain. Pain. 2019;160(4):833-43. https://doi.org/10.1 097/j.pain.0000000000001461.

12. Clark JR, Nijs J, Smart K, et al. Prevalence of extreme trait sensory profiles and personality types in nonspecific chronic low back pain with predominant central sensitization: secondary analysis of an international observational study. Pain physician. 2019;22(3):E181-90 https://www.pa inphysicianjournal.com/current/pdf?article=NjMxMw\%3D\%3D.

13. Qaseem A, Wilt TJ, McLean RM, Forciea MA, for the Clinical Guidelines Committee of the American College of Physicians. Noninvasive treatments for acute, subacute, and chronic low back pain: a clinical practice guideline from the American College of Physicians. Ann Intern Med. 2017;166(7):51430. https://doi.org/10.7326/m16-2367.

14. Shipton EA. Physical therapy approaches in the treatment of low back pain. Pain and therapy. 2018;7(2):127-37. https://doi.org/10.1007/s40122-018-01 05-x.

15. Stochkendahl MJ, Kjaer P, Hartvigsen J, Kongsted A, Aaboe J, Andersen M, et al. National Clinical Guidelines for non-surgical treatment of patients with recent onset low back pain or lumbar radiculopathy. Eur Spine J. 2018;27(1): 60-75. https://doi.org/10.1007/s00586-017-5099-2.

16. Wang $X Q$, Gu W, Chen BL, Wang X, Hu HY, Zheng YL, et al. Effects of whole-body vibration exercise for non-specific chronic low back pain: an assessor-blind, randomized controlled trial. Clin Rehabil. 2019;33(9):1445-57. https://doi.org/10.1177/0269215519848076.

17. Wang R, Weng LM, Peng MS, et al. Exercise for low back pain: a bibliometric analysis of global research from 1980 TO 2018. J Rehabil Med. 2020;52(4):111. https://doi.org/10.2340/16501977-2674

18. de Paula LPO, de Oliveira RR, Costa LOP, et al. Measurement properties of the pressure biofeedback unit in the evaluation of transversus abdominis muscle activity: a systematic review. Physiotherapy. 2011;97(2):100-6. https://doi.org/10.1016/j.physio.2010.08.004.

19. Beazell JR, Grindstaff TL, Hart JM, Magrum EM, Cullaty M, Shen FH. Changes in lateral abdominal muscle thickness during an abdominal drawing-in maneuver in individuals with and without low back pain. Research in sports medicine. 2011;19(4):271-82. https://doi.org/10.1080/15438627.2011.608053.

20. Grooms DR, Grindstaff TL, Croy T, et al. Clinimetric analysis of pressure biofeedback and transversus abdominis function in individuals with stabilization classification low back pain. J Orthopaedic Sports Phys Ther. 2013;43(3):184-93. https://doi.org/10.2519/jospt.2013.4397.

21. Hendrick P, Milosavljevic S, Hale L, Hurley DA, McDonough S, Ryan B, et al. The relationship between physical activity and low back pain outcomes: a systematic review of observational studies. Eur Spine J. 2011;20(3):464-74. https://doi.org/10.1007/s00586-010-1616-2.

22. den Bandt HL, Paulis WD, Beckwée $\mathrm{D}$, et al. Pain mechanisms in low back pain: a systematic review with meta-analysis of mechanical quantitative sensory testing outcomes in people with nonspecific low back pain. J Orthopaedic Sports Phys Ther. 2019;49(10):698-715. https://doi.org/10.2519/jospt.2019.8876.

23. Farasyn AD, Meeusen $\mathrm{R}$, Nijs J. Validity of cross-friction algometry procedure in referred muscle pain syndromes: preliminary results of a new referred pain provocation technique with the aid of a Fischer pressure algometer in patients with nonspecific low back pain. Clin J Pain. 2008;24(5):456-62. https://doi.org/10.1097/AJP.0b013e3181643403.

24. Imamura M, Chen J, Matsubayashi SR, Targino RA, Alfieri FM, Bueno DK, et al. Changes in pressure pain threshold in patients with chronic nonspecific low back pain. Spine. 2013;38(24):2098-107. https://doi.org/10.1 097/01.brs.0000435027.50317.d7.

25. Honoré M, Leboeuf-Yde C, Gagey O, Wedderkopp N. How big is the effect of spinal manipulation on the pressure pain threshold and for how long does it last?-secondary analysis of data from a systematic review.
Chiropractic Manual Ther. 2019;27(1):1-12. https://doi.org/10.1186/s12998-01 9-0240-4.

26. Oliveira R R. AGM Filho, MCF Raposo, and OP Leonardo,"Concurrent validity of the pressure biofeedback unit and surface electromyography in measuring transversus abdominis muscle activity in patients with chronic nonspecific low back pain,". Revista Brasileira de Fisioterapia, 2012, 16(5): 389-395. doi: https://doi.org/10.1590/s1413-35552012 005000038 .

27. Richardson C, Jull G, Toppenberg R, Comerford M. Techniques for active lumbar stabilisation for spinal protection: a pilot study. Aust J Physiother. 1992:38(2):105-12. https://doi.org/10.1016/s0004-9514(14)60555-9.

28. Hodges P, Richardson C, Jull G. Evaluation of the relationship between laboratory and clinical tests of transversus abdominis function. Physiother Res Int. 1996;1(1):30-40. https://doi.org/10.1002/pri.45.

29. Zeni Al, Hoffman MD, Clifford PS. Energy expenditure with indoor exercise machines. Jama. 1996;275(18):1424-7. https://doi.org/10.1001/jama.275.1 8.1424.

30. Vuilleumier PH, Manresa JAB, Ghamri Y, et al. Reliability of quantitative sensory tests in a low back pain population. Regional Anesthesia \& Pain Medicine. 2015;40(6):665-73. https://doi.org/10.1097/aap.0000000000000289.

31. Balaguier $R$, Madeleine $P$, Vuillerme $N$. Is one trial sufficient to obtain excellent pressure pain threshold reliability in the low back of asymptomatic individuals? A test-retest study. PLoS One. 2016;11(8): e0160866. https://doi.org/10.1371/journal.pone.0160866.

32. Balaguier $R$, Madeleine $P$, Vuillerme $N$. Intra-session absolute and relative reliability of pressure pain thresholds in the low back region of vineworkers: effect of the number of trials. BMC Musculoskelet Disord. 2016; 17(1):1-11. https://doi.org/10.1186/s12891-016-1212-7.

33. Gwak G, Hwang U, Jung S, Kim HA, Kim JH, Kwon OY. Comparison of MRI cross-sectional area and functions of core muscles among asymptomatic individuals with and without lumbar intervertebral disc degeneration. BMC Musculoskelet Disord. 2019;20(1):1-9. https://doi.org/10.1186/s12891-019-2 960-y.

34. Cruz-Montecinos C, Bustamante A, Candia-González M, González-Bravo C, Gallardo-Molina P, Andersen LL, et al. Perceived physical exertion is a good indicator of neuromuscular fatigue for the core muscles. J Electromyogr Kinesiol. 2019;49:102360. https://doi.org/10.1016/j.jelekin.2019.102360.

35. Zheng Y, Ke S, Lin C, Li X, Liu C, Wu Y, et al. Effect of core stability training monitored by rehabilitative ultrasound image and surface electromyogram in local core muscles of healthy people. Pain Research and Management. 2019;2019:9130959-8. https://doi.org/10.1155/2019/9130959.

36. Doménech-García V, Palsson TS, Boudreau SA, et al. Pressure-induced referred pain areas are more expansive in individuals with a recovered fracture. Pain. 2018;159(10):1972-9. https://doi.org/10.1097/j.pain. 0000000000001234

37. Boudreau SA, Badsberg S, Christensen SW, Egsgaard LL. Digital pain drawings. Clin J Pain. 2016;32(2):139-45. https://doi.org/10.1097/ajp. 0000000000000230.

38. Kuithan P, Heneghan NR, Rushton A, Sanderson A, Falla D. Lack of exerciseinduced Hypoalgesia to repetitive Back movement in people with chronic low Back pain. Pain Practice. 2019;19(7):740-50. https://doi.org/10.1111/papr.12804.

39. Sullivan MD, Commentary on Higgins, et al. How are chronic pain, psychological distress and opioid dependence related? Addiction. 2020; 115(2):259-60. https://doi.org/10.1111/add.14850.

40. Palermo TM, Slack K, Loren D, Eccleston C, Jamison RN. Measuring and reporting adverse events in clinical trials of psychological treatments for chronic pain. Pain. 2020;161(4):713-7. https://doi.org/10.1097/j.pain. 0000000000001772

41. França FR, Burke TN, Caffaro RR, Ramos LA, Marques AP. Effects of muscular stretching and segmental stabilization on functional disability and pain in patients with chronic low back pain: a randomized, controlled trial. J Manip Physiol Ther. 2012;35(4):279-85. https://doi.org/1 0.1016/j.jmpt.2012.04.012.

42. Park KN, Cynn HS, Kwon OY, Lee WH, Ha SM, Kim SJ, et al. Effects of the abdominal drawing-in maneuver on muscle activity, pelvic motions, and knee flexion during active prone knee flexion in patients with lumbar extension rotation syndrome. Arch Phys Med Rehabil. 2011;92(9):1477-83. https://doi.org/10.1016/j.apmr.2011.03.020.

43. Von Garnier K, Köveker K, Rackwitz B, et al. Reliability of a test measuring transversus abdominis muscle recruitment with a pressure biofeedback unit Physiotherapy. 2009;95(1):8-14. https://doi.org/10.1016/j.physio.2008.10.003. 
44. Cynn HS, Oh JS, Kwon OY, Yi CH. Effects of lumbar stabilization using a pressure biofeedback unit on muscle activity and lateral pelvic tilt during hip abduction in sidelying. Arch Phys Med Rehabil. 2006;87(11):1454-8. https://doi.org/10.1016/j.apmr.2006.08.327.

45. O’Neill S, Kjær P, Graven-Nielsen T, Manniche C, Arendt-Nielsen L. Low pressure pain thresholds are associated with, but does not predispose for, low back pain. Eur Spine J. 2011;20(12):2120-5. https://doi.org/10.1007/ s00586-011-1796-4.

46. Imamura M, Alfieri FM, Filippo TRM, Battistella LR. Pressure pain thresholds in patients with chronic nonspecific low back pain. J Back Musculoskeletal Rehabil. 2016;29(2):327-36. https://doi.org/10.3233/BMR-150636.

47. Hennings A, Schwarz MJ, Riemer S, Stapf TM, Selberdinger VB, Rief W. The influence of physical activity on pain thresholds in patients with depression and multiple somatoform symptoms. Clin J Pain. 2012;28(9):782-9. https:// doi.org/10.1097/AJP.0b013e318243e2d1.

48. Gupta A, McBeth J, Macfarlane GJ, Morriss R, Dickens C, Ray D, et al. Pressure pain thresholds and tender point counts as predictors of new chronic widespread pain in somatising subjects. Ann Rheum Dis. 2007;66(4): 517-21 https://doi.org/10.1136/ard.2006.054650.

49. McPhee ME, Graven-Nielsen T. Recurrent low back pain patients demonstrate facilitated pronociceptive mechanisms when in pain, and impaired antinociceptive mechanisms with and without pain. Pain. 2019, 160(12):2866-76. https://doi.org/10.1097/j.pain.0000000000001679.

50. Saragiotto BT, Maher CG, Yamato TP, Costa LOP, Menezes Costa LC, Ostelo RWJG, et al. Motor control exercise for chronic non-specific low-back pain. Cochrane Database Syst Rev. 2016;1:CD012004. https://doi.org/10.1002/14 651858.Cd012004.

51. Ferreira PH, Ferreira ML, Maher CG, Refshauge K, Herbert RD, Hodges PW. Changes in recruitment of transversus abdominis correlate with disability in people with chronic low back pain. Br J Sports Med. 2010;44(16):1166-72. https://doi.org/10.1136/bjsm.2009.061515.

52. Tsao H, Hodges PW. Immediate changes in feedforward postural adjustments following voluntary motor training. Exp Brain Res. 2007;181(4): 537-46. https://doi.org/10.1007/s00221-007-0950-z.

53. Southwell DJ, Hills NF, McLean L, Graham RB. The acute effects of targeted abdominal muscle activation training on spine stability and neuromuscular control. J Neuroengineering Rehabil. 2016;13(1):1-8. https://doi.org/10.1186/ s12984-016-0126-9.

54. Nambi G, Abdelbasset WK, Alsubaie SF, Moawd SA, Verma A, Saleh AK, et al. Isokinetic training-its radiographic and inflammatory effects on chronic low back pain: A randomized controlled trial. Medicine. 2020;99:51. https://doi. org/10.1097/md.0000000000023555 Isokinetic training - its radiographic and inflammatory effects on chronic low back pain, 99, 51.

55. Jung $K$, Jung J, In T, et al. The effectiveness of trunk stabilization exercise combined with vibration for adolescent patients with nonspecific low Back pain. Int J Environ Res Public Health. 2020;17(19):7024. https://doi.org/10.33 90/ijerph17197024

56. Van Vliet PM, Heneghan NR. Motor control and the management of musculoskeletal dysfunction. Man Ther. 2006;11(3):208-13. https://doi.org/1 0.1016/j.math.2006.03.009.

57. Masse-Alarie H, Beaulieu LD, Preuss $R$, et al. Repetitive peripheral magnetic neurostimulation of multifidus muscles combined with motor training influences spine motor control and chronic low back pain. Clin Neurophysiol. 2017;128(3):442-53. https://doi.org/10.1016/j.clinph.2016.12. 020.

58. Brumagne S, Diers M, Danneels $L$, et al. Neuroplasticity of sensorimotor control in low back pain . journal of orthopaedic \& sports physical therapy, 2019, 49(6): 402-414. doi: https://doi.org/10.2519/jospt.2019.8489

59. Paungmali A, Joseph $L H$, Punturee $K$, Sitilertpisan P, Pirunsan U, Uthaikhup S. Immediate effects of core stabilization exercise on $\beta$-endorphin and cortisol levels among patients with chronic nonspecific low back pain: a randomized crossover design. J Manip Physiol Ther. 2018;41(3):181-8. https://doi.org/10.1016/j.jmpt.2018.01.002.

60. Karlsson L, Gerdle B, Ghafouri B, et al. Intramuscular pain modulatory substances before and after exercise in women with chronic neck pain. European Journal of Pain, 2015, 19(8): 1075-1085. doi:https://doi.org/10.1 002/ejp.630
61. Tsao Henry,Galea Mary P,Hodges Paul W,Driving plasticity in the motor cortex in recurrent low back pain. .Eur J Pain, 2010, 14: 832-839. doi: https:// doi.org/10.1016/j.ejpain.2010.01.001, 8 .

\section{Publisher's Note}

Springer Nature remains neutral with regard to jurisdictional claims in published maps and institutional affiliations.
Ready to submit your research? Choose BMC and benefit from:

- fast, convenient online submission

- thorough peer review by experienced researchers in your field

- rapid publication on acceptance

- support for research data, including large and complex data types

- gold Open Access which fosters wider collaboration and increased citations

- maximum visibility for your research: over $100 \mathrm{M}$ website views per year

At BMC, research is always in progress.

Learn more biomedcentral.com/submissions 